\title{
Desempenho, metabolismo e níveis plasmáticos de colesterol e triglicerídeos em frangos de corte alimentados com óleo ácido e óleo de soja
}

\author{
Performance, metabolism and plasma levels of cholesterol and triglycerides in broilers chickens fed \\ with acidulated soybean soapstock and soybean oil
}

\author{
Marcos Roberto Raber ${ }^{\mathrm{I}}$ Andréa Machado Leal Ribeiro ${ }^{\mathrm{II}}$ Alexandre de Mello Kessler ${ }^{\mathrm{II}}$ \\ Valentino Arnaiz ${ }^{\text {Raquel Valim Labres }}{ }^{\text {III }}$
}

\section{RESUMO}

Neste trabalho são relatados três experimentos (EXP) realizados, sendo dois de desempenho e um de metabolismo. O primeiro experimento de desempenho utilizou 384 pintos de corte machos, da linhagem Cobb 500, e foi conduzido com animais de um a 20 dias de idade. O segundo EXP de desempenho foi realizado com as mesmas aves, após homogeneização de todas elas, com 21 a 34 dias de idade, utilizando-se 256 frangos. $O$ ensaio de metabolismo usou 32 frangos e foi realizado com animais de 21 a 34 dias de idade. Testou-se o óleo ácido de soja (OAS) e o óleo degomado de soja (ODS) incluídos na dieta em quatro níveis (2, 3, 4 e 5\%), constituindo oito tratamentos com quatro repetições cada, dispostos em fatorial $2 \times 4$. Foram avaliados o desempenho e o metabolismo das aves e o coeficiente de metabolismo da matéria seca (CMMS), da gordura bruta (CMGB) e da energia bruta (CMEB) das dietas, além de teores de triglicerídios e colesterol sanguíneo no 34 dia de idade. Nenhuma interação foi observada entre os óleos e os níveis utilizados $(P>0,05)$. Com o aumento do nível de óleo na dieta, observou-se maior peso final das aves $(P<0,01)$ e melhor conversão alimentar (CA) $(P<0,01)$. No EXP de desempenho com animais de um a 21 dias, ocorreu redução no consumo de ração $(P<0,01)$ com a adição de óleo, mas não no EXP com animais de 21 a 34 dias. No ensaio de metabolismo, aves que receberam OAS apresentaram melhor CMMS $(P<0,01)$ em relação ao ODS. O aumento do nível de inclusão de óleo, independentemente do tipo, melhorou o CMMS $(P<0,01)$ e o CMGB $(P<0,01)$ das dietas. Observou-se maiores níveis de triglicerídios no sangue das aves com maiores níveis de óleo $(P<0,01)$. O OAS mostrou eficiência relativa de 93 e 90\% nos EXP de desempenho com animais de um a 20 e de 21 e 34 dias, respectivamente, com base na CA e de 95\%, comparado ao ODS, com base em análise de regressão entre o nível de óleo adicionado $(X)$ e o CMGB $(Y)$ determinado no ensaio de metabolismo. O OAS é uma boa fonte energética para uso em dietas de frangos de corte, apresentando valor energético um pouco inferior ao ODS.

Palavras-chave: desempenho, energia, lipídios, metabolismo.

\section{ABSTRACT}

Three experiments (EXP) were carried on; in two of them the focus was performance and the third consisted in a metabolism study. The first EXP used 384 male Cobb 500 strain chicks and was conducted from one to 20 days of age. The second EXP was conducted with the same birds after all of them were homogenized, from 21 to 34 days, using 256 broilers. The metabolism assay utilized 32 broilers and was carried on from 21 to 34 days. Acidulated soybean soapstock (ASS) and soybean oil (SO) included in four levels (2; 3; 4 and 5\%) were compared, forming eight treatments with four replication each, arranged in a 2x4 factorial. Performance, diet coefficient of metabolism of dry matter (CMDM), of crude fat (CMCF) and of gross energy (CMCE) and also the contents of triglycerides and blood serum cholesterol on the $34^{\text {th }}$ day were evaluated. There was no interaction between oil type and inclusion levels for any response. Increasing oil level in the diet higher body weight $(P<0.01)$ and better feed conversion $(F C)(P<0.01)$ were observed. Only in the first performance EXP, but not in the EXP from 21 to 34 days, reduction in feed intake $(P<0.01)$ by adding oil was observed. In the metabolism assay, birds receiving ASS presented better CMDM $(P<0.01)$, related to SO. Increasing in oil level improved CMDM $(P<0.01)$ and CMCF $(P<0.01)$ of the diets. Higher levels of triglycerides were noticed in the blood serum of birds receaving higher levels of oil $(P<0.01)$. The ASS showed RE of 93 and $90 \%$ in the performance EXP from 1 to 20 and 21 to 34 days, respectively, based on FC and of 95\%, compared to SO, based on regression analysis between oil level added $(X)$ and CMCF (Y), determined in the metabolism assay. ASS is a good energetic source for broiler diets, presenting energetic value a bit lower of the SO.

Key words: energy, fat sources, included level, metabolism, performance.

ICurso de Pós-graduação em Zootecnia, Universidade Federal do Rio Grande do Sul (UFRGS), Porto Alegre, RS, Brasil.

IIDepartamento de Zootecnia, UFRGS. Av. Bento Gonçalves, 7712, 91540-000, Porto Alegre, RS, Brasil. E-mail:aribeiro@ufrgs.br.

*Autor para correspondência.

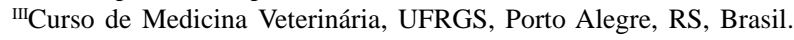




\section{INTRODUÇÃO}

O óleo ácido de soja (OAS), obtido após a acidificação da borra resultante do processo de refino do óleo degomado de soja (ODS), é uma matéria-prima que pode substituir tradicionais insumos na fabricação de ração para aves. A borra é gerada a partir do processo de refino por meio da neutralização alcalina do óleo bruto. Esta (também conhecida por soapstock) representa cerca de 2 a 3\% do óleo de soja bruto, e apresenta 60 a 80\% de ácidos graxos livres (AGL), que estando saponificados serão recuperados com a adição de ácido sulfúrico. O uso do OAS é vantajoso, uma vez que esse resíduo aumentaria a poluição ambiental caso não aproveitado.

Embora o OAS venha sendo largamente utilizado pela indústria avícola, ainda há certa relutância quanto ao seu uso. Isso se deve principalmente à incerteza quanto ao seu valor energético, mas também à alta concentração de AGL em sua composição, à variação na composição destes AGL e à presença de impurezas que podem desgastar os equipamentos usados nas fábricas de ração.

A utilização das gorduras pelas aves depende da hidrólise dos triglicerídios pela lipase pancreática e de sua emulsificação pela bile. Um trabalho clássico na área mostrou que a eficiência desse processo depende da presença de monoglicerídios e do comprimento e da saturação de cadeia dos ácidos graxos (HOFMANN \& BORGSTRÖM, 1962). WISEMAN et al. (1991) verificaram redução no conteúdo de energia metabolizável aparente (EMA) de fontes de gordura para aves à medida que o nível de saturação ou de ácidos graxos livres foi aumentado.

Quando substitui-se ODS por quantidades iguais de OAS, ocorre perda de desempenho de frangos de corte, o que é um indicativo de que este possui menor valor energético que o ODS (SKLAN, 1979; GAIOTTO et al., 2000). A principal explicação seria a menor proporção da gordura total na forma de triglicerídios. VIEIRA et al. (2002), comparando o OAS com o ODS, verificaram que a EMA do OAS, medida em frangos de corte, foi em torno de 5\% inferior à EMA do ODS. FREITAS et al. (2005) observaram valores de EMA para o OAS de $7488 \mathrm{kcal} \mathrm{kg}^{-1}$ em pintos, de 12-20 dias de idade e de $8610 \mathrm{kcal} \mathrm{kg}^{-1}$, em galos adultos, valor este bastante próximo ao do ODS (8790 kcal $\mathrm{kg}^{-1}$ ), sugerido por ROSTAGNO et al. (2005).

Quanto à qualidade do produto carne que é um aspecto cada vez mais exigido por parte dos consumidores, FERREIRA et al. (1999) concluíram que os níveis de energia empregados nas rações de frangos de corte alteraram os teores de colesterol encontrados no peito, na coxa e na pele de frangos. RADCLIFFE \& TRAMPOSCH (1988) observaram em codornas que o colesterol plasmático e hepático aumentava com a elevação do colesterol na dieta.

Assim, o objetivo dste trabalho foi comparar a eficiência biológica do OAS baseada nas respostas de desempenho e de metabolismo (comparação matemática das curvas de desempenho e de metabolismo das aves alimentadas com cada tipo de óleo) e determinar seu nível energético, bem como avaliar os níveis sanguíneos de colesterol e triglicerídios das aves. Para alcançar estes objetivos foram usadas dietas com níveis crescentes e similares das duas fontes lipídicas apresentadas como OAS e ODS.

\section{MATERIAL E MÉTODOS}

Foram realizados dois experimentos (EXP) de desempenho e um ensaio de metabolismo nas instalações do Laboratório de Ensino Zootécnico (LEZO) da UFRGS, em 2005. Considerou-se três experimentos porque, apesar dos tratamentos manterem-se os mesmos nos EXP I e II, todas as aves, no final do EXP I (animais de um a 20 dias) foram misturadas e realocadas aleatoriamente nas repetições dos EXP II (21 a 34 dias), a fim de evitar o efeito residual caso fossem consideradas duas fases de um mesmo experimento. O ensaio de metabolismo também ocorreu entre os dias 21 e 34 de idade das aves (EXP III). Em todos os EXP as aves foram submetidas a oito tratamentos em que foram avaliados dois tipos de óleo (ODS e OAS) e quatro níveis de inclusão (2, 3, 4 e 5\%) na dieta basal (DB). A adição de óleo ocorreu em substituição ao material inerte (areia fina) na DB. As dietas foram isonutritivas, exceto para os níveis de gordura incorporados, e conseqüentemente a EMA estimada também diferiu. A DB atendeu as exigências nutricionais para cada fase (NRC, 1994) (Tabela 1). O ODS foi adquirido no mercado local, enquanto que o OAS foi adquirido da empresa Sulina Comércio de Óleos Ltda. Para efeito de formulação, considerou-se ambos os tipos com mesma quantidade de energia metabolizável por quilograma ( $\mathrm{kcal} \mathrm{EM} \mathrm{kg}^{-1}$ ) (VIEIRA et al., 2002).

No experimento I, de 1 a 20 dias, foram utilizados 384 pintos de corte, machos, da linhagem Cobb 500, distribuídos em 32 gaiolas de $0,72 \mathrm{~m}^{2}$ cada, em sala climatizada, aonde foram ajustadas as temperaturas para a faixa de conforto de acordo com a idade. O EXP II utilizou 256 aves, distribuídos em 32 gaiolas de $1 \mathrm{~m}^{2}$ cada. Nos dois EXP o peso médio inicial da repetições ficou dentro de um intervalo de 3\% acima ou abaixo da média de todas as repetições $(\mu \pm 3 \%)$. A 
Tabela 1 - Composição percentual das dietas experimentais na matéria natural.

\begin{tabular}{|c|c|c|c|c|c|c|c|c|}
\hline Ingredientes & \multicolumn{4}{|c|}{ Dieta basal inicial (\%) } & \multicolumn{4}{|c|}{ Dieta basal crescimento (\%) } \\
\hline Milho & \multicolumn{4}{|c|}{51,35} & \multicolumn{4}{|c|}{55,82} \\
\hline Farelo de soja & \multicolumn{4}{|c|}{38,17} & \multicolumn{4}{|c|}{34,04} \\
\hline Fosfato bicálcico & \multicolumn{4}{|c|}{1,90} & \multicolumn{4}{|c|}{1,76} \\
\hline Calcário & \multicolumn{4}{|c|}{1,22} & \multicolumn{4}{|c|}{1,17} \\
\hline Premix vit ${ }^{1} \min ^{-2}$ & \multicolumn{4}{|c|}{0,50} & \multicolumn{4}{|c|}{0,40} \\
\hline Sal & \multicolumn{4}{|c|}{0,46} & \multicolumn{4}{|c|}{0,43} \\
\hline DL- Metionina & \multicolumn{4}{|c|}{0,25} & \multicolumn{4}{|c|}{0,19} \\
\hline Lisina & \multicolumn{4}{|c|}{0,10} & \multicolumn{4}{|c|}{0,15} \\
\hline Colina & \multicolumn{4}{|c|}{0,05} & \multicolumn{4}{|c|}{0,04} \\
\hline Óleo (\%) & 2,00 & 3,00 & 4,00 & 5,00 & 2,00 & 3,00 & 4,00 & 5,00 \\
\hline Areia Fina (\%) & 4,00 & 3,00 & 2,00 & 1,00 & 4,00 & 3,00 & 2,00 & 1,00 \\
\hline \multicolumn{9}{|c|}{ Composição nutricional } \\
\hline EB $\left(\mathrm{kcal} \mathrm{kg}^{-1}\right)-\mathrm{ODS}^{3}$ & 3712 & 3772 & 3871 & 4026 & 3558 & 3820 & 3903 & 3917 \\
\hline $\mathrm{EB}\left(\mathrm{kcal} \mathrm{kg}^{-1}\right)-\mathrm{OAS}^{3}$ & 3735 & 3753 & 3863 & 3963 & 3772 & 3811 & 3926 & 4048 \\
\hline EM $\left(\mathrm{kcal} \mathrm{kg}^{-1}\right)^{4}$ & 2795 & 2883 & 2971 & 3060 & 2853 & 2941 & 3029 & 3120 \\
\hline Proteína Bruta (\%) & \multicolumn{4}{|c|}{21,50} & \multicolumn{4}{|c|}{20,00} \\
\hline Cálcio (\%) & \multicolumn{4}{|c|}{0,97} & \multicolumn{4}{|c|}{0,91} \\
\hline Fósforo disp ( \%) & \multicolumn{4}{|c|}{0,45} & \multicolumn{4}{|c|}{0,42} \\
\hline Sódio (\%) & \multicolumn{4}{|c|}{0,20} & \multicolumn{4}{|c|}{0,18} \\
\hline Colina (mg kg-1) & \multicolumn{4}{|c|}{1500} & \multicolumn{4}{|c|}{1400} \\
\hline Lisina digestível $^{5}(\%)$ & \multicolumn{4}{|c|}{1,10} & & & & \\
\hline Met + Cis dig. ${ }^{5}(\%)$ & & & & & & & & \\
\hline Treonina $^{5}$ & & & & & & & & \\
\hline Triptofano ${ }^{5}$ & & & & & & & & \\
\hline
\end{tabular}

${ }^{1}$ Composição por kg de ração, respectivamente, para fase inicial e crescimento: vit. A 10.000 e 8. 000UI; vit. D3 3.000 e 2.000 UI; vit. E 60 e 30mg; vit. K3 3 e 2mg; vit. B1 3 e 2mg; vit. B2 8 e 6mg; vit. B6 4 e 2,5mg; vit. B12 0,014 e 0,012mg; ác. pantotênico 20 e $15 \mathrm{mg}$; ác. fólico 2 e $1 \mathrm{mg}$; niacina 50 e 35mg; biotina 0,15 e $0,08 \mathrm{mg}$.

${ }^{2}$ Composição por kg de ração para ambas as fases: ferro 40mg; zinco 80mg; manganês 80mg; cobre 10mg; iodo 0,7mg; selênio 0,3mg.

${ }^{3}$ Análises realizadas no Laboratório de Nutrição Animal da UFRGS.

${ }^{4}$ Estimativa de EM considerando valores iguais de EM para ODS e OAS (VIEIRA et al., 2001).

${ }^{5}$ Adaptado de Rostagno, 2005.

iluminação foi contínua e alimento e água foram fornecidos à vontade. As avaliações de desempenho foram feitas semanalmente através de medidas do peso corporal (PV), ganho de peso (GP), consumo de ração (CR) e conversão alimentar (CA).

No ensaio de metabolismo foram utilizados 32 frangos de corte, linhagem Cobb 500, com peso similar, distribuídos em gaiolas individuais de 0,25x0,33m cada, com bandejas metálicas para as coletas das excretas. A iluminação foi contínua e a água foi fornecida à vontade. A ração foi fornecida uma vez ao dia, de forma restrita, de modo que as aves recebessem 90\% do consumo voluntário individual (SCHNEIDER \& FLATT, 1975), tendo como base o consumo normal da linhagem para a idade. A restrição no consumo voluntário foi adotada visto que o consumo é um fator determinante no resultados de metabolismo. O ensaio foi conduzido durante 14 dias, com coleta diária total e individual de excretas das aves durante todo o período, as quais, juntamente com as amostras das rações experimentais foram analisadas para matéria seca (MS) (SILVA, 1990), gordura bruta (GB), energia bruta (EB) (AOAC, 1990; RIBEIRO et al., 2001) no Laboratório de Nutrição Animal da UFRGS. Com base nos resultados das análises, foram calculados os coeficientes de metabolismo da MS (CMMS), GB(CMGB) eEB(CMEB) utilizando-se as equações propostas por MATTERSON et al. (1965).

No 34 ${ }^{\circ}$ dia do experimento de metabolismo, realizou-se coleta de sangue dos 32 animais, por meio da veia ulnar de uma das asas, para posterior análise de triglicerídios e colesterol. O colesterol foi determinado pelo método enzimático-colorimétrico do colesterol esterase/colesterol oxidase e os triglicerídios foram determinados pelo método enzimático com lipase, por meio de leitura de absorbância em 505nm, por reação de ponto final no Laboratório de Análises Clínicas Veterinárias da UFRGS.

Ciência Rural, v.38, n.6, set, 2008. 
Utilizou-se um delineamento experimental inteiramente casualizado, em esquema fatorial $2 \times 4$, com quatro repetições por tratamento de 12 , oito e um ave por repetição, nos EXP I e II e III, respectivamente. Os dados coletados foram submetidos à análise de variância (SAS, 2001) e a comparação de médias foi feita pelo teste LSmeans (SAS, 2001). Foi também feita análise de regressão para os níveis de óleo, com relação aos dois tipos de óleo (slope ratio tecnique), permitindo a interpretação da eficiência biológica do OAS em substituição ao ODS. Eficiência biológica foi entendida como a comparação das curvas de desempenho dos animais submetidos a níveis crescentes de cada tipo de óleo. Com as respostas obtidas no ensaio de metabolismo, também foi usado o Lucas Teste, descrito por VAN SOEST (1994), para calcular a metabolizabilidade da gordura dos dois tipos de óleo. Esta resposta foi obtida por meio de análise de regressão, tendo como variável independente $(\mathrm{X})$ o percentual de gordura adicionado à dieta e como variável dependente $(\mathrm{Y})$ o coeficiente de metabolismo da gordura bruta da dieta (CMGB). A inclinação da reta correspondeu à metabolizabilidade do ODS $\left(\mathrm{M}_{\mathrm{ODS}}\right) \mathrm{e}$ do OAS ( $\left.\mathrm{M}_{\mathrm{OAS}}\right)$.

A energia metabolizável dos óleos foi calculada por meio da seguinte fórmula: $\mathrm{EM}_{\mathrm{ODS}}=$
$\mathrm{M}_{\mathrm{ODS}} * \mathrm{~EB}_{\mathrm{ODS}} ; \mathrm{EM}_{\mathrm{OAS}}=\mathrm{M}_{\mathrm{OAS}} * \mathrm{~EB}_{\mathrm{OAS}}$, em que, $\mathrm{M}$ representa a metabolizabilidade do óleo em questão e a EB representa a energia bruta do óleo obtida na bomba calorimétrica.

\section{RESULTADOS E DISCUSSÃO}

No experimento de desempenho de um a 20 dias (EXP I), não foi observada interação ( $\mathrm{P}>0,05)$ entre o tipo e o nível de óleo para nenhuma das respostas (Tabela 2). As aves ajustaram o $\mathrm{CR}$ aos níveis crescentes de óleo, reduzindo-o $(\mathrm{P}<0,01)$ com o incremento de óleo na dieta. Apesar da diminuição do CR, o incremento de óleo melhorou o $\mathrm{PV}(\mathrm{P}<0,01)$, o GP $(\mathrm{P}<0,01)$ e a $\mathrm{CA}(\mathrm{P}<0,01)$. O provável aumento da energia líquida das rações, devido à inclusão de óleo, explica os resultados de desempenho. Já o menor CR pode ser vantajoso, pois LONGO (2000) observou que as aves apresentam menor aproveitamento da dieta com aumento de consumo, pela diminuição da eficiência de ação das enzimas digestivas e, conseqüentemente, menor absorção de nutrientes.

Na comparação dos dois tipos de óleo, pôde ser observado que o OAS proporcionou maior CR $(\mathrm{P}<0,01)$ pelos pintos, embora isso não tenha refletido em maior GP ou PV. No entanto, estas aves

Tabela 2 - Desempenho de frangos de corte recebendo dietas contendo óleo degomado de soja (ODS) ou óleo ácido de soja (OAS) em quatro níveis de inclusão (EXP I - um a 20 dias e EXP II - 21 a 34 dias).

\begin{tabular}{|c|c|c|c|c|c|c|c|c|}
\hline & \multicolumn{4}{|c|}{----------Experimento I (1 a 20 dias)---------- } & \multicolumn{4}{|c|}{----------Experimento II (21 a 34 dias)---------- } \\
\hline & ${ }^{1}$ PV20 (g) & ${ }^{2} \mathrm{GP}(\mathrm{g})$ & ${ }^{3} \mathrm{CR}(\mathrm{g})$ & ${ }^{4} \mathrm{CA}\left(\mathrm{kg} \mathrm{kg}^{-1}\right)$ & ${ }^{5} \mathrm{PV} 34(\mathrm{~g})$ & ${ }^{6} \mathrm{GP}(\mathrm{g})$ & CR (g) & ${ }^{7} \mathrm{CA}\left(\mathrm{kg} \mathrm{kg}^{-1}\right)$ \\
\hline \multicolumn{9}{|c|}{ Tipos de Óleo } \\
\hline ODS & 874 & 832 & $1138^{\mathrm{B}}$ & $1,37^{\mathrm{A}}$ & 2190 & 1300 & 2200 & $1,69^{\mathrm{A}}$ \\
\hline OAS & 890 & 852 & $1183^{\mathrm{A}}$ & $1,40^{\mathrm{B}}$ & 2190 & 1290 & 2240 & $1,74^{\mathrm{B}}$ \\
\hline $\mathrm{P}$ & 0,1 & 0,08 & 0,001 & 0,01 & 0,8 & 0,5 & 0,1 & 0,03 \\
\hline \multicolumn{9}{|c|}{ Níveis de Óleo } \\
\hline $2 \%$ & $855^{\mathrm{B}}$ & $813^{\mathrm{B}}$ & $1180^{\mathrm{A}}$ & $1,45^{\mathrm{C}}$ & $2140^{\mathrm{C}}$ & $1240^{\mathrm{C}}$ & 2240 & $1,81^{\mathrm{C}}$ \\
\hline $3 \%$ & $882^{\mathrm{AB}}$ & $839^{\mathrm{AB}}$ & $1200^{A}$ & $1,43^{\mathrm{C}}$ & $2190^{\mathrm{B}}$ & $1290^{\mathrm{B}}$ & 2200 & $1,72^{\mathrm{B}}$ \\
\hline $4 \%$ & $887^{\mathrm{A}}$ & $846^{\mathrm{A}}$ & $1130^{\mathrm{B}}$ & $1,34^{\text {В }}$ & $2210^{\text {B }}$ & $1310^{\mathrm{AB}}$ & 2230 & $1,69^{\text {в }}$ \\
\hline $5 \%$ & $904^{\mathrm{A}}$ & $862^{\mathrm{A}}$ & $1130^{\mathrm{B}}$ & $1,31^{\mathrm{A}}$ & $2250^{\mathrm{A}}$ & $1350^{\mathrm{A}}$ & 2200 & $1,63^{\mathrm{A}}$ \\
\hline $\mathrm{P}$ & 0,01 & 0,01 & 0,001 & 0,001 & 0,001 & 0,001 & 0,8 & 0,001 \\
\hline$r^{2}$ & 0,46 & 0,48 & 0,70 & 0,86 & 0,60 & 0,62 & 0,18 & 0,66 \\
\hline CV (\%) & 2,9 & 3,0 & 2,6 & 2,1 & 1,7 & 2,9 & 3,6 & 3,3 \\
\hline
\end{tabular}

PV 20 e 34ํำ dia: peso corporal ao $20^{\circ}$ e $34^{\circ}$ dia, respectivamente; GP: ganho de peso; CR: consumo de ração; CA: conversão alimentar; ODS: óleo degomado de soja; OAS: óleo ácido de soja.

Médias seguidas de letras diferentes nas colunas, diferem entre si pelo teste Lsmens.

${ }^{1}$ Efeito linear PV20 = 0,8293 + 0,0149 * nível, $\mathrm{r}^{2}=0,30, \mathrm{P}<0,001$.

${ }^{2}$ Efeito linear GP $=0,787+0,0151 *$ nível, $\mathrm{r}^{2}=0,30, \mathrm{P}<0,0001$.

${ }^{3}$ Efeito linear $\mathrm{CR}=1,237-0,0222 *$ nível, $\mathrm{r}^{2}=0,28, \mathrm{P}<0,002$.

${ }^{4}$ Efeito linear $\mathrm{CA}=1,5618-0,0514 *$ nível, $\mathrm{r}^{2}=0,73, \mathrm{P}<0,0001$.

${ }^{5}$ Efeito linear PV21 $=2,0740+0,0346 *$ nível, $\mathrm{r}^{2}=0,56, \mathrm{P}<0,0001$.

${ }^{6}$ Efeito linear GP $=1,175+0,035 *$ nível, $\mathrm{r}^{2}=0,57, \mathrm{P}<0,0001$.

${ }^{7}$ Efeito linear CA $=1,909-0,0552 *$ nível, $\mathrm{r}^{2}=0,54, \mathrm{P}<0,0001$. 
apresentaram pior $\mathrm{CA}(\mathrm{P}<0,01)$ aos 20 dias, resposta semelhante àquela obtida no trabalho de VIEIRA et al. (2002). Estas respostas são uma indicação de que o OAS tem menor valor energético que o ODS.

A eficiência biológica, baseada no GP, medida por meio da técnica do slope ratio, mostrou retas com inclinações diferentes $(\mathrm{P}<0,05)$ para os dois tipos de óleo: $G P(O D S)=0,7909+0,0119 *$ nível; GP(OAS)=0,7909+0,0173*nível, $r^{2}=0,42$. A interpretação destas inclinações mostra uma eficiência energética relativa do OAS em relação ao ODS de 145 \% (0,0173/ 0,0119). Salienta-se, no entanto, que o coeficiente de determinação foi baixo, o que indica pouca confiabilidade nas estimativas, quer pela variabilidade da resposta medida (o que não é o caso de variáveis do tipo ganho de peso), quer pelo fato do modelo testado não ser adequado à dispersão dos resultados observados (SAMPAIO, 1998). Na regressão entre níveis de óleo e $\mathrm{CA}$, as inclinações das retas não diferiram $(\mathrm{P}>0,05)$, tendo sido obtidas as seguintes equações: $\quad \mathrm{CA}(\mathrm{ODS})=1,5561-0,0536^{*}$ nível; CA(OAS)=1,5561-0,0498*nível, $\mathrm{r}^{2}=0,82$. Nesse caso, com um coeficiente de determinação maior, a eficiência energética relativa do OAS foi de 93\%.

No experimento de desempenho de 21 a 34 dias de idade (EXP II), por meio da ANOVA, também não foi observada interação significativa $(\mathrm{P}>0,05)$ entre o tipo e o nível de óleo. Nesta fase houve diferença significativa $(\mathrm{P}<0,01)$ para nível de óleo sobre GP, PV e $\mathrm{CA}$, mas não sobre $\mathrm{CR}$, diferentemente do que aconteceu no EXP I. O desempenho dos animais recebendo OAS foi similar ao daqueles recebendo ODS, com exceção para a CA, que se mostrou melhor $(\mathrm{P}<0,05)$ para o ODS ao contrário dos achados de VIEIRA et al. (2002), que também usando a mesma matriz energética para ambos os óleos, não observaram diferenças na CA.

Para a comparação da eficiência biológica baseada no GP, pela técnica do slope ratio, as inclinações das retas dos dois tipos de óleo não diferiram significativamente $(\mathrm{P}>0,84)$. As seguintes equações foram obtidas: $\operatorname{GP}(\mathrm{ODS})=1,1837+$ 0,033*nível; GP(OAS)=1,1837+0,032*nível, $\mathrm{r}^{2}=0,54$. A eficiência relativa do OAS, para GP, foi de $97 \%$ em relação ao ODS. Para a CA as retas também não tiveram diferentes inclinações $(\mathrm{P}>0,25)$. Abaixo, as equações: $\mathrm{CA}(\mathrm{ODS})=1,902$ - 0,059*nível; CA(OAS) = 1,902 $0,053 *$ nível, $\mathrm{r}^{2}=0,65$. Nesse caso, a eficiência relativa do OAS foi de $90 \%$ em relação ao ODS.

Pintos jovens têm menor capacidade de reabsorver os sais biliares devido à imaturidade da circulação entero-hepática, menor atividade da lipase e menor digestibilidade aparente dos lipídios (LEESON
\& SUMMERS, 1997; NIR et al., 1993; FRIZZAS, 1996; ZELENKA et al., 2000). No entanto, os resultados comparativos entre os EXP I e II mostram que as linhagens de conformação atuais têm grande capacidade de aproveitar lipídios da dieta, inclusive óleos ácidos. Mesmo que o OAS tenha menor capacidade de formar micelas (SKLAN, 1979), os resultados do presente trabalho indicam que a eficiência relativa, tendo como base a CA, pela técnica do slope ratio, foi de $93 \%$ aos 20 dias e de $90 \%$ aos 34 dias de idade dos frangos. É importante salientar, entretanto, que as inclinações das retas não diferiram significativamente. Os dados são próximos dos obtidos por VIEIRA et al. (2002), que sugeriram um valor energético de 95\% para o OAS, quando comparado com o ODS.

No ensaio de metabolismo (EXP III), também não houve interação $(\mathrm{P}>0,05)$ entre o tipo e o nível de óleo para nenhuma resposta medida (Tabela 3). Foi observado maior CMMS para OAS $(\mathrm{P}<0,01)$ em comparação com o ODS. Para os CMGB e CMEB, não foram observadas diferenças entre os tipos de óleo testados. Estes resultados se contrapõem à hipótese de que a menor proporção de triglicerídeos presente do OAS reduz a ativação da secreção de bile e a formação de micelas em aves (WISEMAN \& SALVADOR, 1991). Contrariamente aos achados desse trabalho, Vieira et al. (2002) observaram que o ODS teve melhor CMEB, em frangos de 28 a 30 dias. Na comparação dos níveis testados, pode ser observado que à medida que houve maior inclusão de óleo o CMMS $(\mathrm{P}<0,01)$ e CMGB $(\mathrm{P}<0,001)$ melhoraram, sem alteração do CMEB $(\mathrm{P}>0,05)$, independentemente do tipo de óleo.

$\mathrm{Na}$ figura 1 estão representadas graficamente as retas e as equações resultantes da regressão pelo Lucas teste (VAN SOEST, 1994). Nas equações, o valor de “b” representa a metabolizabilidade da gordura dos óleos testados. Para o ODS, a metabolizabilidade foi de 95,5\%; e para o OAS foi de $90,8 \%$, sendo que os coeficientes diferiram significativamente entre si $(\mathrm{P}<0,01)$. Em termos relativos, a eficiência do OAS em fornecer gordura às aves foi de 95,0\% em relação ao ODS.

A EMA calculada, por meio da fórmula descrita no material e métodos foi para ODS e OAS de 8.977 e $8.478 \mathrm{kcal} \mathrm{kg}^{-1}$, respectivamente. VIEIRA et al. (2002) obtiveram 8.540 e $8.114 \mathrm{kcal} \mathrm{kg}^{-1}$ para ODS e OAS, respectivamente, em frangos de 28 a 30 dias. Observase que a relação entre OAS e ODS foi mantida, nos dois experimentos, ao redor de $95 \%$.

Quanto aos teores de triglicerídios e colesterol (Tabela 3), não houve interação $(\mathrm{P}>0,05)$ entre o tipo e o

Ciência Rural, v.38, n.6, set, 2008. 
Tabela 3 - Coeficiente de metabolismo da Matéria Seca (CMMS), da Gordura Bruta (CMGB) e da Energia Bruta (CMEB), teores de triglicerídios e colesterol sanguíneos aos 34 dias de idade de frangos de corte recebendo óleo degomado de soja (ODS) e óleo acido de soja (OAS), em quatro níveis de inclusão (EXP III).

\begin{tabular}{|c|c|c|c|c|c|}
\hline & CMMS(\%) & CMGB(\%) & CMEB (\%) & $\begin{array}{l}\text { Triglicerídios } \\
\quad\left(\mathrm{mg} \mathrm{dL}^{-1}\right)\end{array}$ & Colesterol (mg dL $\left.\mathrm{dL}^{-1}\right)$ \\
\hline \multicolumn{6}{|c|}{ Tipos de óleo } \\
\hline ODS & $65,6^{\mathrm{B}}$ & 72,9 & 76,9 & 48 & 142 \\
\hline OAS & $67,6^{\mathrm{A}}$ & 70,0 & 76,8 & 54 & 144 \\
\hline $\mathrm{P}$ & 0,001 & 0,05 & 0,3 & 0,4 & 0,9 \\
\hline \multicolumn{6}{|c|}{ Níveis de óleo } \\
\hline $2 \%$ & $65,5^{\mathrm{B}}$ & $66,4^{\text {B }}$ & 76,2 & $46^{\mathrm{B}}$ & 138 \\
\hline $3 \%$ & $65,9^{\mathrm{B}}$ & $69,9^{\text {B }}$ & 76,1 & $41^{\mathrm{B}}$ & 138 \\
\hline $4 \%$ & $68,1^{\mathrm{A}}$ & $74,4^{\mathrm{A}}$ & 77,6 & $60^{\mathrm{A}}$ & 152 \\
\hline $5 \%$ & 66,9 АВ & $75,2^{A}$ & 76,6 & $57^{\mathrm{A}}$ & 144 \\
\hline $\mathrm{P}$ & 0,01 & 0,001 & 0,08 & 0,001 & 0,09 \\
\hline$r^{2}$ & 0,65 & 0,54 & 0,38 & 0,33 & 0,23 \\
\hline CV (\%) & 3,8 & 9,7 & 2,9 & 27,1 & 11,8 \\
\hline
\end{tabular}

Médias seguidas de letras diferentes nas colunas diferem entre si pelo teste LSmeans.

nível de óleo. Da mesma forma, não se observou diferença significativa $(\mathrm{P}>0,05)$ para o tipo de óleo nas respostas analisadas. Por outro lado, constatou-se que os menores níveis de inclusão apresentaram menores teores de triglicerídios $(\mathrm{P}<0,01)$ no sangue. Já os níveis de colesterol não foram afetados nem pelo tipo de óleo, nem pela adição de óleo. Comparativamente a GONZÁLEZ et al. (2001), os valores de triglicerídios obtidos no presente estudo estão dentro da normalidade. No entanto, os níveis médios de colesterol estão acima dos normais.

A utilização do OAS em rações animais é dependente de garantias mínimas de qualidade, como a manutenção de um produto sem adulteração pela inclusão de outros óleos de baixa qualidade. Nesse sentido, os fornecedores necessitam garantir um padrão para os óleos ácidos quanto à umidade, as impurezas, ao teste de saponificação e à acidez, da mesma forma que os demais óleos produzidos. Porém, tão ou mais importante que a garantia de qualidade do produto é o valor energético do mesmo na formulação de rações.

\section{CONCLUSÕES}

O OAS é uma alternativa ao uso do ODS em dietas, tanto na fase inicial quanto na fase de

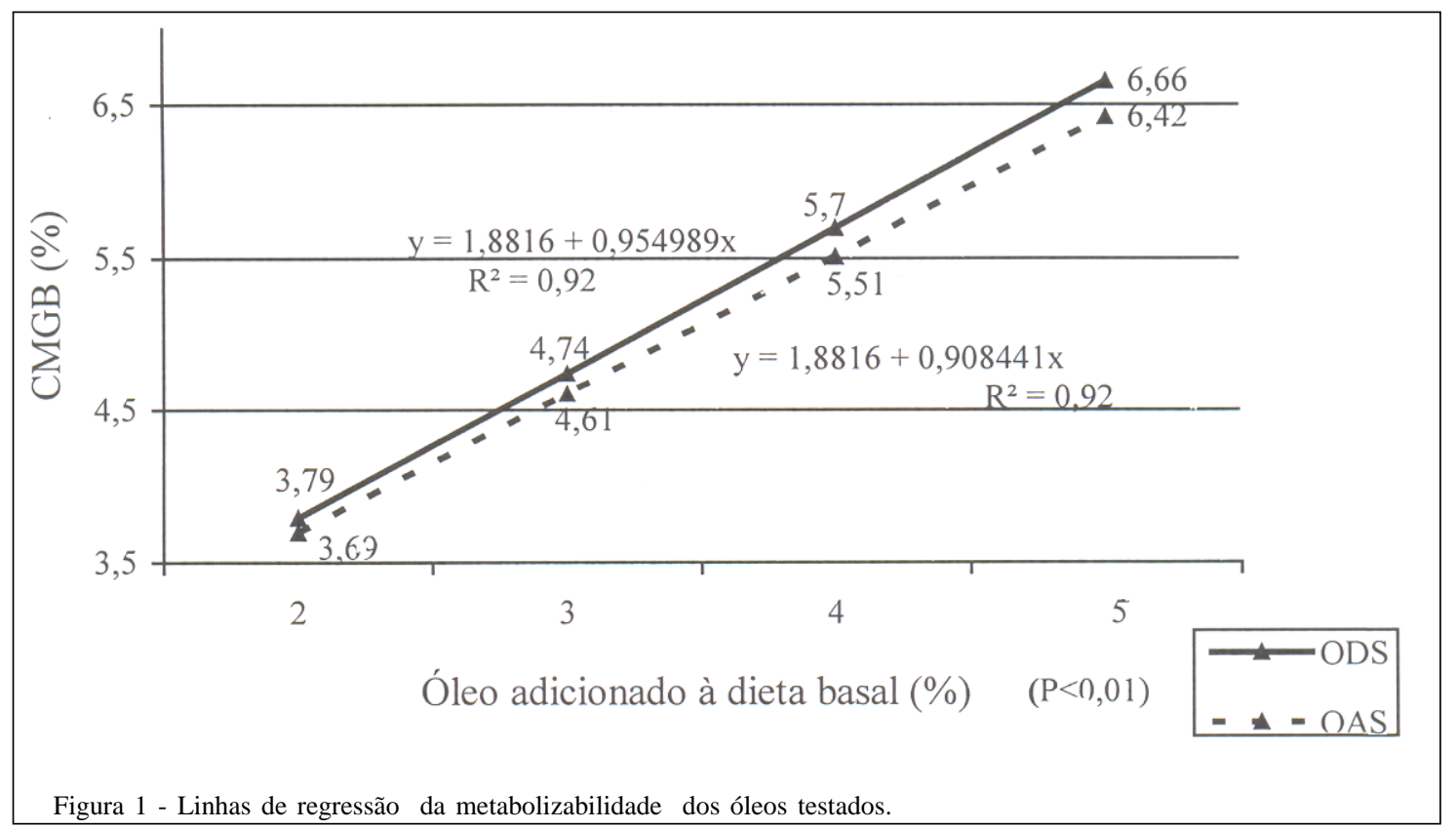

Ciência Rural, v.38, n.6, set, 2008. 
crescimento de frangos de corte. Sustentado pelo desempenho ou pelo metabolismo, o valor do óleo ácido em relação ao óleo de soja foi de 90 a 95\%. A adição de até $5 \%$ de óleo, independentemente do tipo, não influenciou os níveis de colesterol sangüíneo das aves.

\section{AGRADECIMENTOS}

Ao Conselho Nacional de Desenvolvimento Científico e Tecnológico (CNPq), pela bolsas de produtividade e mestrado de Andréa M.L Ribeiro e Marcos V. Raber, respectivamente.

\section{REFERÊNCIAS}

ASSOCIATION OF OFFICIAL ANALYTICAL CHEMISTRY - AOAC. Official methods of analysis. 15.ed. Arlington: AOAC International, 1990. Supl 2.

FERREIRA, J.M. et al. Efeito de tipo de óleo adicionado à dieta, sobre o teor de colesterol em partes da carcaça de frangos de corte de acordo com sexo e linhagem. Revista Ciência e Tecnologia de Alimentos v.19, p.189-193, 1999.

FREITAS, R.E. et al. Valor energético do óleo ácido de soja para aves. Pesquisa Agropecuária Brasileira, v.40, p.241246, 2005.

FRIZZAS, A.C. Efeito do uso de probióticos sobre o desempenho e a atividade de enzimas digestivas de frangos de corte. 1996. 70f. Dissertação (Mestrado em Zootecnia) - Faculdade de Ciências Agrárias e Veterinárias de Jaboticabal, Universidade Estadual Paulista.

GAIOTTO, J.B. et al. Óleo de soja, óleo ácido de soja e sebo bovino como fontes de gordura em rações para frangos de corte. Revista Brasileira de Ciência Avícola v.2, p.219-227, 2000.

GONZÁLEZ, F.H.D. et al. Incidência de doenças metabólicas em frangos de corte no sul do Brasil e uso do perfil bioquímico sanguíneo para o seu estudo. Revista Brasileira de Ciência Avícola, v.3, p.141-147, 2001.

HOFMANN, A.F.; BORGSTRÖM, B. Physico-chemical sate of lipids in intestinal content during their digestion and absorption. Federation Proceedings, v.21, p.43-50, 1962.

LEESON, S.; SUMMERS, J.D. Commercial poultry nutrition. 2.ed. Guelph: University Books, 1997. 356p.

LONGO, F.A. Estudo do metabolismo energético e do crescimento em frangos de corte. 2000. 76f. Dissertação (Mestrado em Zootecnia) - Faculdade de Ciências Agrárias e Veterinárias de Jaboticabal, Universidade Estadual Paulista.

MATTERSON, L.D. et al. The metabolizable energy of feed ingredients for chickens. Storrs, Connecticut: The University of Connecticut - Agricultural Experiment station, 1965. V.7, p.3-11. (Research Report, 7).
NATIONAL RESEARCH COUNCIL - NRC. Nutrient requirement of poultry. 9.ed. Washington D.C.: National Academy of Sciences, 1994. p.155.

NIR, I. et al. Comparative growth and development of the digestive organs and some enzymes in broiler and egg type chicks after hatching. British Poultry Science, v.34, p.523532, 1993.

RADCLIFFE, J.D.; TRAMPOSCH, T.S. The effect of dietary cholesterol level on lipid status and initiation of atherosclerosis in Japanese quail. Nutrition Research, v.8, p.1021-1027, 1988.

RIBEIRO, A.M.L. et al. Comparison of different drying techniques for nitrogen analysis of poultry excreta, feces and tissue. Journal of Applied Poultry Research, v.10, n.1, p.21-23, 2001.

ROSTAGNO, H.S. et al. Tabelas brasileiras para aves e suínos: composição de alimentos e exigências nutricionais. 2.ed. Viçosa, MG: UFV, 2005. 186p.

SAMPAIO, I.B.M. Estatística aplicada à experimentação animal. Belo Horizonte: Fundação de Ensino e Pesquisa em Medicina Veterinária e Zootecnia, 1998. 221p.

SAS, Statistic analysis system. Painless Windows, a handbook for SAS users. 2.ed. Guelph: Jodie Gilmore, 2001. 61p.

SILVA, D.J. Análise de alimentos (métodos químicos e biológicos). 2.ed. Viçosa, MG: UFV, 1990. 165p.

SCHNEIDER, B.H.; FLATT, W.P. The evaluation of feeds through digestibility experiments. Athens: University of Georgia, 1975. 423p.

SKLAN, D. Digestion and absorption of lipids in chicks fed triglycerides or free fatty acids: synthesis of monoglycerides in the intestine. Poultry Science, v.58, p.885-889, 1979.

VAN SOEST, P.J. Nutritional ecology of the ruminant. 2.ed. New York: Cornell University, 1994. V.36, p.360-363.

VIEIRA, S.L. et al. Utilização da energia de dietas para frangos de corte formuladas com óleo ácido de soja. Revista Brasileira de Ciência Avícola, v.4, p.127-139, 2002.

WISEMAN, J.; SALVADOR, F. The influence of free fatty acid content and degree of saturation on the apparent metabolizable energy value of fats fed broilers. Poultry Science, v.70, p.573582, 1991.

WISEMAN, J. et al. Prediction of the apparent metabolizable energy content of fats fed to broiler chickens. Poultry Science, v.70, p.1527-1533, 1991.

ZELENKA, J. et al. Apparent digestibility of fat and nitrogen retention in young chicks. Czech Journal of Animal Science, v.45, p.457-462, 2000. 